\title{
Caspases in metabolic disease and their therapeutic potential
}

\author{
Claire H Wilson ${ }^{1} \cdot$ Sharad Kumar $^{1}$ \\ Received: 10 January 2018 / Revised: 26 February 2018 / Accepted: 22 March 2018 \\ (c) The Author(s) 2018. This article is published with open access
}

\begin{abstract}
Caspases, a family of cysteine-dependent aspartate-specific proteases, are central to the maintenance of cellular and organismal homoeostasis by functioning as key mediators of the inflammatory response and/or apoptosis. Both metabolic inflammation and apoptosis play a central role in the pathogenesis of metabolic disease such as obesity and the progression of nonalcoholic steatohepatisis (NASH) to more severe liver disease. Obesity and nonalcoholic fatty liver disease (NAFLD) are the leading global health challenges associated with the development of numerous comorbidities including insulin resistance, type-2 diabetes and early mortality. Despite the high prevalence, current treatment strategies including lifestyle, dietary, pharmaceutical and surgical interventions, are often limited in their efficacy to manage or treat obesity, and there are currently no clinical therapies for NAFLD/NASH. As mediators of inflammation and cell death, caspases are attractive therapeutic targets for the treatment of these metabolic diseases. As such, pan-caspase inhibitors that act by blocking apoptosis have reached phase I/II clinical trials in severe liver disease. However, there is still a lack of knowledge of the specific and differential functions of individual caspases. In addition, cross-talk between alternate cell death pathways is a growing concern for long-term caspase inhibition. Evidence is emerging of the important cell-death-independent, nonapoptotic functions of caspases in metabolic homoeostasis that may be of therapeutic value. Here, we review the current evidence for roles of caspases in metabolic disease and discuss their potential targeting as a therapeutic strategy.
\end{abstract}

\section{Facts}

(1) Caspases can mediate the inflammatory response and apoptotic cell death to maintain organismal homoeostasis

(2) Caspase-dependent apoptosis is involved in the pathogenesis of obesity and progression of severe $\mathrm{NASH}$

(3) Blocking apoptosis in NASH with pan-caspase inhibitors shows therapeutic potential in clinical studies

(4) Caspase inhibition has not been investigated in the context of obesity

Edited by G. Melino.

Claire H Wilson

claire.wilson@unisa.edu.au

$\triangle$ Sharad Kumar

sharad.kumar@unisa.edu.au

1 Centre for Cancer Biology, University of South Australia \& SA Pathology, Adelaide, SA 5001, Australia

\section{Open questions}

(1) How do caspases differentially regulate metabolism?

(2) Which specific caspases have non-apoptotic roles in metabolic disease?

(3) What are the critical caspase substrates mediating metabolic functions?

(4) Can caspases or their specific substrates be therapeutically targeted in obesity?

\section{Introduction}

Caspases are a family of evolutionary conserved cysteinedependent aspartate-specific proteases that play crucial roles in maintaining organismal homoeostasis throughout life [1]. Mammalian caspases are broadly classified as being inflammatory/pyroptotic (human caspase-1, $-4,-5$ and -12 , murine caspase-1, -11 and -12), or as initiators (human and murine caspase-2, -8, -9 and human caspase-10) and executioners (human and murine caspase- $3,-6$ and -7 ) of apoptotic cell death [1]. Caspase-14 is more difficult to classify but is not involved in cell death [1]. In mice, 


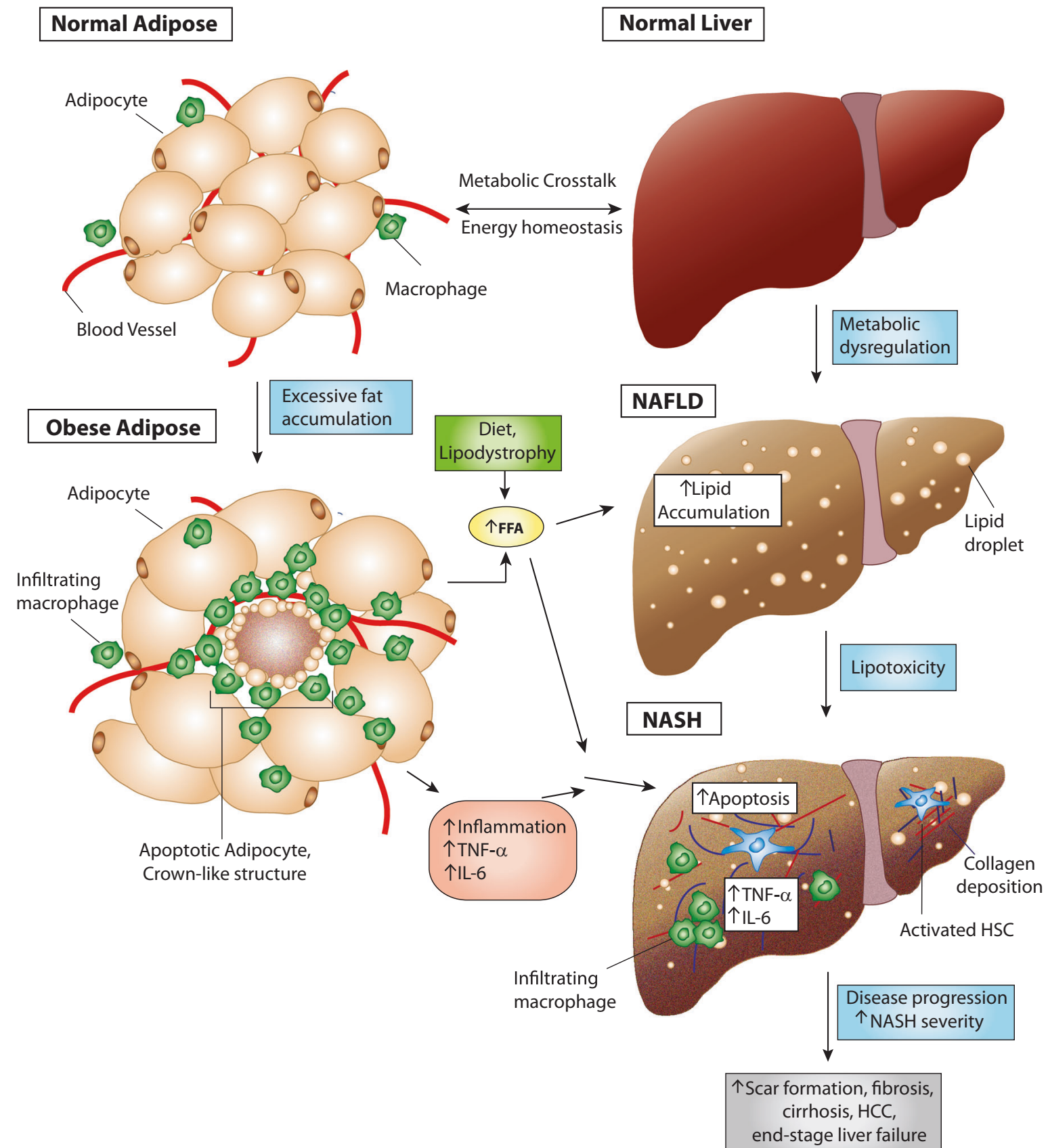

Fig. 1 Metabolic cross-talk and apoptosis in the progression of obesity and NAFLD/NASH. In obesity, excessive fat accumulation results in overexpansion of adipose tissue, resulting in adipocyte cell death which promotes inflammatory macrophage infiltration and adipose/ metabolic dysfunction. Increases in circulating FFA from obese adipose tissue and/or from diet contribute to the excessive accumulation of lipids in the liver and development of NAFLD. Release of inflammatory cytokines from adipose tissue further contributes to liver

caspase-11 is the murine orthologue of human caspase-4 and -5 . Apoptosis occurs via two main pathways: the extrinsic death-receptor pathway (e.g. Fas/CD95, TNFR) or the intrinsic pathway via mitochondrial outer membrane permeabilisation (MOMP). In both cases, the activation of inflammation, metabolic dysfunction and hepatocyte cell death. Progression of NAFLD to NASH to more severe NASH involves marked increases in hepatocyte apoptosis, resulting in hepatic stellate activation, collagen deposition, scarring and fibrosis. Abbreviations: FFA free fatty acids, HCC hepatocellular carcinoma, HSC hepatic stellate cell, IL interleukin, NAFLD nonalcoholic fatty liver disease, NASH nonalcoholic steatohepatitis, TNF tumour necrosis factor

initiator caspases following their dimerisation through caspase activation platforms leads to subsequent effector caspase activation, cleavage of a large number of cellular substrates and apoptosis [1]. In response to damageassociated molecular patterns (DAMPs) or pathogen- 


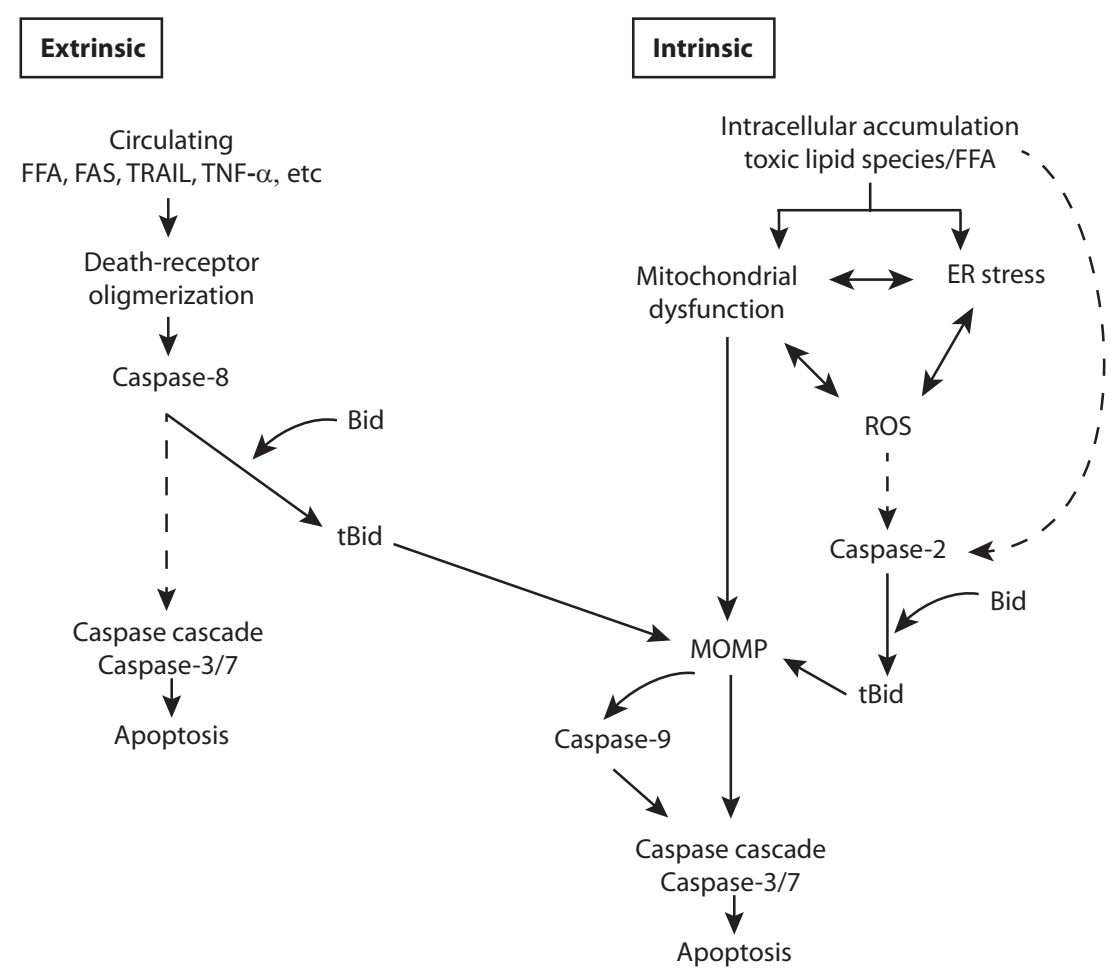

Fig. 2 Apoptotic pathways in metabolic disease. Caspase-dependent extrinsic and intrinsic apoptotic pathways are induced in response to increases in circulating FFAs, cytokines and intracellular accumulation of toxic lipid species/FFA via increases in mitochondrial dysfunction and ER stress. Extrinsic apoptosis mainly involves activation of the initiator caspase-8, followed by activation of executioner caspases and/ or cleavage of Bid, followed by induction of MOMP and subsequent executioner caspase activation. Intrinsic apoptotic pathways can occur

associated molecular patterns (PAMPs), the activation of inflammatory caspases, particularly caspase-1, results in maturation of inflammatory cytokines and pyroptosis, an alternative form of cell death [2]. Caspases also have roles independent of inflammation and cell death with importance of their non-apoptotic functions increasingly becoming apparent [1].

Apoptosis plays a central role in the pathogenesis of obesity and progression of nonalcoholic steatohepatitis (NASH) to more severe liver disease (e.g. cirrhosis, hepatocellular carcinoma and end-stage liver failure) $[3,4]$. The therapeutic potential of blocking apoptosis through use of pan-caspase inhibitors in liver injury and disease has been demonstrated in animal models and initial clinical studies (some ongoing) [5] but is yet to be investigated in the context of obesity. However, the precise function of specific caspases is still unclear, and evidence of cross-talk between alternative cell death pathways may complicate therapeutic blocking of apoptosis to treat metabolic diseases. Due to high overlap in substrate selectivity among caspase family members, there is currently a lack of available specific small-molecule inhibitors, although a number of via many pathways involving caspase-dependent and independent pathways. Upstream of the MOMP, caspase-2 is activated in response to stress-induced signals including ROS. Precise mechanisms of apoptotic pathways in metabolic disease are still unknown. Abbreviations: ER endoplasmic reticulum, FFA free fatty acids, MOMP mitochondria outer membrane permeabilisation, TNF tumour necrosis factor, TRAIL TNF-related apoptosis-inducing ligand, ROS reactive oxygen species

compounds have been patented [6, 7]. Therefore, novel targeting strategies involving nanoparticle siRNA delivery or future utilisation of CRISPR-Cas9 gene-editing approaches may be required to therapeutically ablate individual caspases. Firstly, however, better knowledge of the nonapoptotic roles and the precise mechanism of individual caspase functions need to be established. Furthermore, elucidation of the mechanism of caspase functions with identification of their specific proteolytic substrates may prove to be of benefit for future therapeutics.

\section{Apoptosis in the pathogenesis of obesity and progression of NASH}

Obesity, characterised by excessive accumulation of fat, involves impaired lipid storage with dysfunction and overexpansion of white adipose tissue (WAT), leading to toxic accumulation of lipids in non-adipose tissue (e.g. liver and skeletal muscle) (Fig. 1) [8, 9]. In obesity, WAT overexpansion primarily occurs via increases in adipocyte size (hypertrophy) and number (hyperplasia) [8]. Hypertrophy 
occurs to a certain limit before it triggers cell death that precedes hyperplasia to maintain or increase lipid-storage capacity $[4,10,11]$. Adipocyte size positively correlates with increased caspase activation, adipocyte apoptosis, insulin resistance and inflammation in obese mice and humans [4, 10, 12]. Adipocyte cell death promotes infiltration of adipose tissue macrophages that aggregate in crown-like structures to remove apoptotic bodies and lipiddroplet remnants. This coincides with the release of proinflammatory cytokines and mediators (TNF- $\alpha$, IL-6 and iNOS) that promote a state of low-grade chronic inflammation (Fig. 1) [10, 13]. Morphologically, adipocyte cell death resembles the ultrastructural features of necrosis and pyroptosis [13, 14], although involvement of apoptosis in this process is also well documented [4]. Targeted apoptotic deletion of adipocytes via induction of caspase- 8 activation using the FAT-ATTAC mouse model has demonstrated the role of apoptosis in the recruitment of inflammatory macrophages and formation of crown-like structures $[15,16]$.

Nonalcoholic fatty liver disease (NAFLD), characterised by hepatic accumulation of lipids in the absence of alcohol, results from imbalances in the uptake of circulating free fatty acids (FFA) and/or increases in hepatic de novo lipogenesis accompanied by decreased fatty-acid output [17]. Although obesity is one of the major risk factors for the development of NAFLD, it also occurs in lean people and disorders where primary lipid storage is impaired or absent (e.g. lipodystrophies) (Fig. 1) [18]. NASH, a more severe form of NAFLD, is distinguished from simple steatosis by the presence of massive hepatocellular death (primarily apoptosis), hepatocellular ballooning, inflammation and fibrosis [3]. Although multiple forms of cell death (pyroptosis, necroptosis and autophagy-dependent cell death) have been identified, hepatocyte apoptosis plays a key role in driving disease progression with the formation of apoptotic bodies further promoting inflammatory infiltration and activation of collagen-producing hepatic stellate cells that promote fibrogenesis (Fig. 1) [19, 20].

\section{Mechanisms of apoptosis in metabolic disease}

In obesity and $\mathrm{NASH}$, caspase-dependent apoptotic cell death can be initiated by both the extrinsic and intrinsic signalling pathways (Fig. 2), although the precise mechanism is still unknown [4, 12, 21]. In obese human adipose tissue, increased levels of active caspase- $3,-7$ and -9 protein and caspase-3/7 activity along with decreased phosphorylation of anti-apoptotic $\mathrm{Bcl} 2$ protein have been detected [12]. Induction of CASP9 and CASP3/7 transcripts was also detected in the obese adipose tissue [12], although it is important to note that changes in CASP gene expression do not necessarily infer changes in levels of apoptosis which is a post-translational mechanism. As the primary initiator of the extrinsic apoptotic pathway, caspase- 8 has a central role in obesity and NASH. Extrinsic apoptosis typically involves ligand-dependent activation of cell death receptors (e.g. Fas, TNF- $\alpha$ and TRAIL) via binding of their cognate ligands, triggering the formation of an intracellular death-inducing signalling complex (DISC) that recruits and activates caspase-8 [1]. Caspase- 8 can then directly activate caspase-3 or cleave Bid to trigger MOMP, indirectly activating caspases and apoptosis similar to the intrinsic pathway (Fig. 2) [22]. Notably, caspase- 8 can also be activated by intrinsic signals [22]. Increases in circulating FasL correlate with hepatocyte apoptosis and disease severity in NASH patients [21]. The toxic accumulation of FFA, particularly long-chain saturated fatty acids and other lipid species (e.g. free cholesterol, ceramide), can lead to increased reactive oxygen species (ROS) formation, mitochondria dysfunction, TNF- $\alpha$ production and activation of several stress pathways, including ER stress and JNK activation $[17,23,24]$. Release of TNF- $\alpha$ from adipose tissue into the circulation, can further promote local cell death by the extrinsic TNFR-mediated pathway contributing significantly to hepatocellular death in the liver (Fig. 1) [9]. Increases in circulating FFA can also trigger extrinsic apoptosis by stimulating TRAIL death-receptor 2-mediated signalling [25, 26] and by sensitising cells to cytokine toxicity (Fig. 2) [24]. Intrinsic apoptosis typically involves oligomerisation of $\mathrm{BAK}$ or $\mathrm{BAX}$ at the mitochondria, resulting in MOMP and release of cytochorome $\mathrm{c}$ that binds to apoptotic protease-activating factor 1 (APAF1) to form the apoptosome. Apoptosome activates caspase-9 which then cleaves and activates caspase- 3 to trigger apoptosis (Fig. 2) [22]. Caspase-2 has been implicated to be important for hepatocellular apoptosis in NASH, as discussed further below [27, 28]. Although not required for intrinsic apoptosis, caspase- 2 is activated in response to intrinsic signals and is known to cleave Bid and function both upstream and downstream of MOMP to initiate or propagate the apoptotic signal (Fig. 2) [1]. As mentioned above, some caspases are also involved in alternative cell death pathways, thus providing cross-talk between apoptosis and other means of cellular demise. Furthermore, the roles of several caspases, including caspase-1, $-2,-3$ and -8 in metabolic homoeostasis and disease have been reported.

\section{Cross-talk between caspases and alternate cell death pathways in metabolic disease}

For therapeutic targeting of caspases addressed later in this paper, it is important to discuss the issue of alternate cell death pathways and cross-talk between them. Due to cross- 
talk between different cell death pathways and morphological similarities, it is very difficult to differentiate between different modalities of cell death in vivo [29]. Death via both pyroptosis and necroptosis results in lytic cell death, and apoptosis can result in secondary necrosis if the resulting apoptotic bodies are not removed by scavenger cells [29]. It has become increasingly evident that failure of one mode of cell death can result in alternative 'back-up' modes of death being triggered, both dependent and independent of caspases, that are important to acknowledge when considering blocking of apoptosis via caspase inhibition as a therapeutic option (discussed later in this paper). With regard to metabolic disease, these alternate cell death pathways have important roles in propagating local inflammation and trigger further apoptosis or pyroptosis of surrounding cells following the release of DAMPs and inflammatory cytokines. In addition to apoptotic and regulated cell death, accidental or necrotic death can be increased following blockage of programmed cell death [29].

Pyroptosis primarily occurs via cleavage of gasdermin D by caspases-1, $-4,-5$ and 11 [30]. Cleavage results in release and translocation of a $\mathrm{N}$-terminal fragment of gasdermin $\mathrm{D}$ that oligomerises at the plasma membrane forming pyroptotic pores that result in cell swelling and membrane rupture [30]. Recently, it has been shown that other gasdermin family members (six in humans) also form pores at the plasma membrane and induce pyroptosis and this can involve caspase cleavage [30]. Effector caspases-3 and -6 were reported to cleave gasdermin B and gasdermin D within their pore-forming domain, suggesting that during apoptosis, caspases may inactivate gasdermins to prevent pyroptosis [30]. However, caspase-3 has also been shown to cleave and activate gasdermin $\mathrm{E}$, resulting in a switch from apoptotic to secondary necrotic/pyroptosis death in response to chemotherapeutic drugs, TNF- $\alpha$ and viral infection [31]. While highly relevant in the context of metabolic disease as discussed in this paper, it needs to be fully established if gasdermin $\mathrm{E}$ is present in hepatocytes and/or adipocytes as its expression seems to be limited to only certain cell types [30]. Caspase- 8 has also been proposed to function upstream and downstream of the NLRP3 inflammasome, and it has been suggested that a fine-tuned balance may exist between pyroptosis and apoptosis [32]. Furthermore, activation of the NLRP3 inflammasome has also been reported downstream of necroptosis induction [32]. Thus, communication between these various cell death pathways needs to be further defined.

In the context of caspase inhibition, when MOMP reaches a certain level, it has been shown that caspase inhibition can have limited effect in stopping apoptosis and can indeed result in increased inflammatory signalling following the release of mitochondrial DNA [33].
Mitochondrial DNA in the cytosol triggers the innate immune cGAS/STING pathway, resulting in type-I interferon production by dying cells. The apoptotic caspase cascade generally suppresses this mtDNA-induced cGAS/STING signalling to ensure that cell death does not result in an immune response. Thus, an inhibition of caspases can result in increased secretion of IFN- $\beta$ [33]. This can in turn promote DAMP signalling and may further exacerbate local inflammation and progression of metabolic disease.

While caspase- 8 has a key role in extrinsic apoptosis, it is also critical in suppression of necroptosis. Like pyroptosis, necroptosis is a form of programmed lytic cell death and morphologically the two forms of cell death can be identical [29]. Necroptosis involves activation of intracellular receptor-interacting protein kinase 3 (RIPK3) followed by phosphorylation of mixed-lineage kinase domain-like (MLKL) which then binds and oligmerises at the plasma membrane, forming necroptotic pores that result in cellular swelling, plasma membrane rupture (lysis) and release of cytosolic DAMPs in an analogous manner to gasdermins in pyroptosis [29]. While RIPK3 can be activated by intracellular signals, extrinsic TNFR signalling via RIPK1 can trigger RIPK3 activation. Typically, RIPK1 recruits FADD, resulting in caspase- 8 activation, leading to apoptosis and blockade of the inflammatory necroptotic pathway via caspase-8-mediated cleavage of CYLD, and in this manner, caspase- 8 has a dominant pro-survival effect during embryogenesis and hematopoiesis [34]. Thus, necroptosis only occurs in the absence or inhibition of caspase- 8 activity. Regulation and cross-talk of alternative cell death pathways is tightly regulated and the mechanisms are still widely unknown. While a number of pro- and anti-apoptotic molecules are known, an important protein in the context of metabolic disease is the anti-apoptotic caspase- 8 homologue cellular FLICE-inhibitor (cFLIP) protein [29]. cFLIP has a high affinity for binding to procaspase- 8 and can inhibit its binding and activation to FADD to supress apoptosis, while depending on the levels of cFLIP, it can also help promote activation of caspase- 8 and inhibit necroptosis via formation of a caspase-8-c-FLIP complex [35]. While more in-depth discussion of multiple forms of cell death is reviewed elsewhere [29], complexities and therapeutic implications of caspase inhibition are further discussed below.

\section{Caspase- 1 in metabolic inflammation and metabolic disease}

As an important component of the NLRP3 inflammasome, activation of caspase- 1 has been shown to be associated with metabolic inflammation and disease, however, its precise role remains unclear due to inconsistent findings 


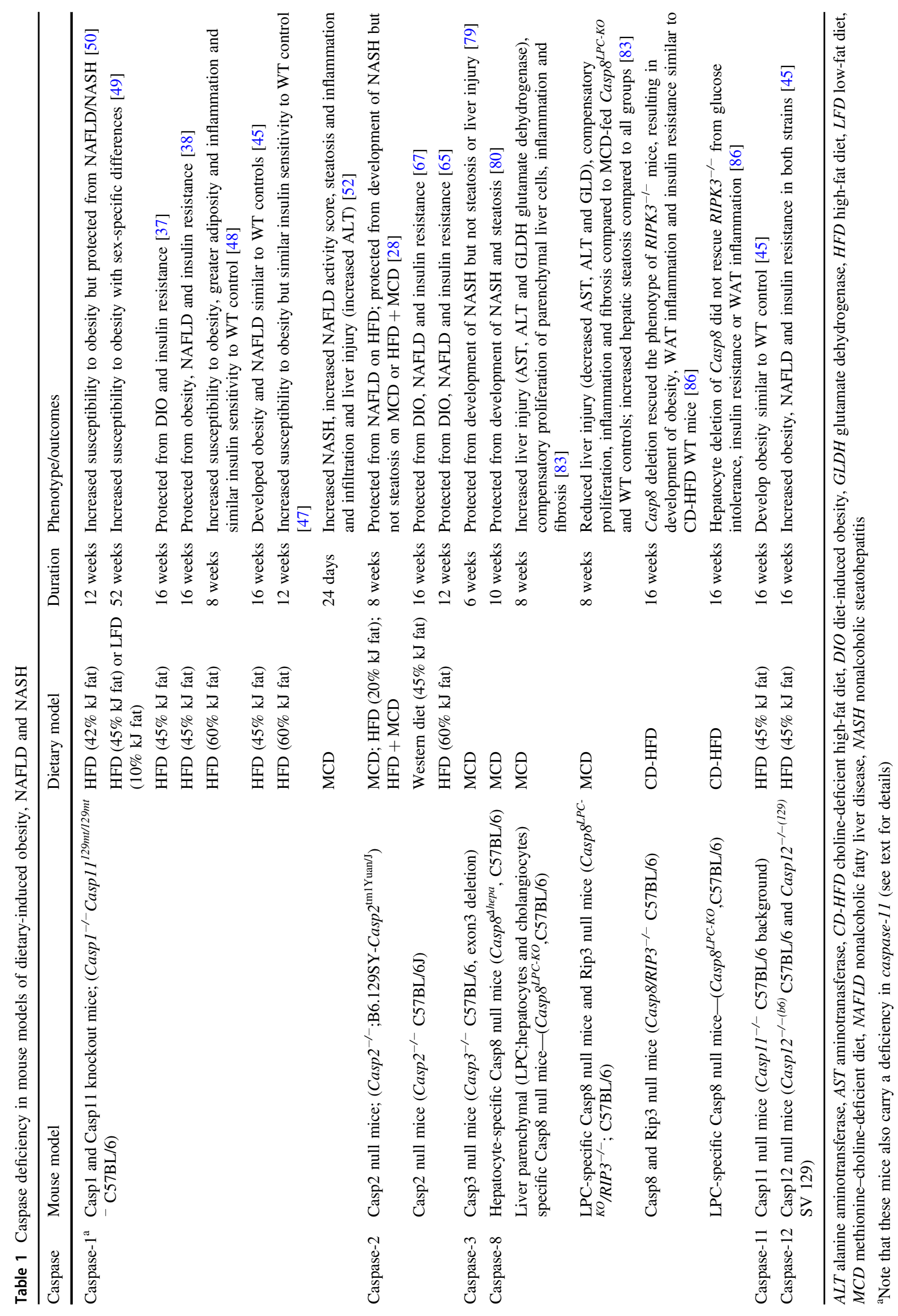


from knockout animal studies (Table 1). Release of DAMPs and lipotoxicity can result in activation of the NLRP3 inflammasome and caspase- 1 in macrophages and adipose tissue [36], and increased expression and activation of caspase-1 has been observed in mouse models of diet-induced obesity (DIO) and genetically obese $d b / d b$ and $o b / o b$ mice [37-39]. Increased activation of caspase-1 has also been demonstrated during hyperglycaemia in mouse and human adipose tissue [39]. Activation of caspase-1 triggers an inflammatory response by its cleavages of proinflammatory interleukins (IL) $1-\beta$ and IL-18 to their mature forms and initiates pyroptotic cell death via cleavage of gasdermin-D [2, 40] as described above. In addition, caspase- 1 has been linked with metabolism via its cleavage of sterol-regulatory binding proteins (SREBPs), peroxisome proliferator-activated gamma (PPAR $\gamma$ ) and glycolytic enzymes (discussed further below) [41-43].

Importantly, the Casp1 $^{-1-}$ mice used in a number of studies (Table 1) are also deficient for Casp11, the murine homologue of human $C A S P 4 / 5$, due to the strain of 129 mice used to firstly generate the initial knockouts, before backcrossing to C57BL/6 mice, containing a mutation in the Casp11 locus that attenuates its expression [44]. Thus, these mice are referred to as Casp1 $1^{-/-}$Casp $^{129 m t / 129 m t}$ in Table 1 although they are discussed as being $\operatorname{Casp1}^{-/-}$in the below text. Since the discovery of this dual knockout, caution is needed in interpreting results from Caspl knockout animal studies as there may be an exacerbated or reduced response from combined deficiency of Caspl on Caspl1-deficient background. To date, only a single study has looked at the potential separate role of caspase-11 in metabolism by utilising Casp11-specific knockout mice generated on a C57/BL6 background expressing WT Caspl [45]. In that study, Casp $11^{-/-}$mice showed no difference in their susceptibility to HFD-induced obesity compared to WT mice and displayed similar changes in weight and total fat mass to the Casp $^{-/-}$Casp $^{129 m t / 129 m t}$ mice although the double knockouts accumulated significantly more epididymal adipose tissue [45].

In mice, caspase-1 (combined with caspase-11, as discussed above) deficiency has been shown to result in reduced total fat mass, smaller adipocyte size, better insulin sensitivity and enhanced adipogenesis [37, 39]. The knockout mice were found to be protected from DIO reportedly due, in part, to an increase in whole-body fatty-acid oxidation [37]. As smaller adipocytes are known to be more insulin sensitive and more 'metabolically' active, this study indicates that the absence of caspase-1 leads to 'healthier' fat-mass/expansion of fat. However this is yet to be fully validated. Subsequently, in a separate study, the same group reported that increases in energy expenditure and enhanced faecal output also contributed to protection from DIO [38]. Following this, it was reported that the knockout mice had reduced intestinal absorption of dietary lipids, enhance hepatic triglyceride excretion and increased clearance of circulating triglycerides [46]. Enhanced triglyceride clearance, but not altered intestinal lipid absorption or hepatic clearance, was also observed in $\mathrm{Casp1}^{-1-}$ mice by Kotas et al.; however, this study, along with several other studies found Caspl deficiency to be paradoxically more susceptible to the development of HFD-induced obesity (Table 1) [47-50]. While it is possible that gut microbiota and loss of Casp11 (as discussed above) can contribute to these inconsistencies, further studies are clearly needed to establish whether targeting caspase- 1 is of therapeutic value in obesity.

Metabolic inflammation involving NLRP3 inflammasomemediated activation of caspase- 1 and hepatocyte pyroptosis has been reported to play a crucial role in the progression of NAFLD to NASH [51], and Caspl ${ }^{-1-}$ mice fed with a methionine-choline diet (MCD) for 4 weeks showed signs of exacerbated NASH [52]. NLRP3 inflammasome activation following ER stress, triggers caspase-1-mediated pyroptosis and positively correlates with liver injury in NASH patients [53]. In addition, Casp1 $1^{-1-}$ mice fed with a MCD diet for 4 weeks showed signs of exacerbated NASH [52]. Paradoxically, protection of $\mathrm{Caspl}^{-/-}$mice from HFD-induced $\mathrm{NASH}$ has also been reported, although in that study, Caspl -/- mice still developed obesity [50].

Chronic ER stress is a common feature of metabolic disease that can contribute to the development of insulin resistance [54] and ER stress-induced apoptosis can be induced by multiple pathways [55]. Although caspase-2 was initially reported to be a major effector of ER stressinduced apoptosis [56] controversy now surrounds this [57]. ER stress has also been linked with induction of pyroptosis with NLRP3 inflammasome and caspase-1 activation positively correlating with ER markers and liver injury in NASH patients [53].

Other inflammatory caspases have also been investigated in the context of metabolic disease with knockout animal studies, suggesting that murine caspase-12 may have a protective role in the progression of obesity [45]. Caspase-12 has also been shown to inhibit caspase-1 and block the inflammatory response, although its catalytic activity is not required for this [58, 59]. Human caspase12 protein is catalytically inactive and thus considered to be a pseudogene [60]. Furthermore, the expression of functional caspase-12 protein is absent in most human populations due to a premature stop codon in human CASP12 [60], except in a small population of sub-Saharan African descendants carrying a SNP in CASP12 and who consequently have weakened inflammatory and innate immune responses [61]. 


\section{Caspase-2 function in metabolic disease}

Caspase- 2 is the most evolutionarily conserved member of the caspase family [1, 62]. Recent evidence indicates a role for caspase-2 in metabolic homoeostasis. In mice, caspase-2 deficiency results in reduced maximal body weight, decreased total fat mass $[63,64]$ and smaller white adipocyte size [65-67]. Casp $2^{-1-}$ mice also have reduced fasting blood glucose and are protected from the development of age-induced glucose intolerance. This is despite Casp2 $2^{-/-}$ mice displaying a mild premature ageing phenotype, in part due to enhanced susceptibility to oxidative stress-induced damage and an impaired antioxidant response system [63, 68]. Recent data suggest that Casp2 $2^{-/-}$mice have an increased preference for whole-body carbohydrate utilisation [65], but the mechanism of this phenotype has not been established. Importantly, these metabolic phenotypes in Casp $2^{-1-}$ mice appear to be independent of apoptosis, as no detectable differences in cell death have been found in adipose tissue or liver under normal dietary conditions [63, $65,66]$. However, the apoptotic function of caspase-2 appears to be important in the progression of severe NASH $[27,28]$.

Caspase-2 has been implicated in saturated fatty-acidinduced apoptosis (lipoapoptosis) [69] and in addition to caspase-8, is activated in response to ceramide-induced apoptosis [70]. While one study reported protection from western diet-induced liver injury in $\operatorname{Casp}^{2^{-/-}}$mice [67], this is likely to be a secondary effect of overall protection from obesity. In addition, no detectable difference in hepatocellular apoptosis has been found in other studies employing Casp $2^{-/-}$ animals [63, 65, 66, 68, 71, 72]. However, increased activation of caspase-2 is observed in patients with more severe NASH compared to those with simple steatosis [21] and Casp2 ${ }^{-/-}$ mice are protected from MCD-induced NASH [28].

Two independent studies have found that Casp $2^{-/-}$mice are protected from the development of DIO, NAFLD and insulin resistance (Table 1) [65, 67]. Although both studies observed a decrease in obese adipocyte apoptosis, this is likely a consequence of overall reduced susceptibility to obesity and does not provide evidence for direct involvement of caspase-2 in this context [65, 67]. While Machado et al. suggested that protection from DIO partly involves increases in fatty-acid oxidation in Casp $2^{-/-}$mice [67], this was not consistent with the indirect calorimetry studies [65]. Nevertheless, findings from both studies suggest that caspase-2 alters mature adipocyte metabolism of fats and/or that adipogenesis is enhanced which would consequently result in healthier expansion of fat mass $[65,67]$. This includes the presence of smaller adipocytes, maintenance of WAT PPARy, FABP4 and adiponectin levels and evidence of WAT browning (increased $U C P 1$ expression) following HFD or western-diet feeding [65, 67]. Studies involving lineage tracing in mouse show that brown or 'beige'-like adipocytes are generated mainly de novo from pre-adipocyte cells and not via transdifferentiation of mature adipocytes [11]. Machado et al. also observed increased proliferation of adipose-derived stem cells from Casp $2^{-/-}$mice [67]. These studies indicate a potential role for caspase- 2 as a target in obesity, however, as with the other caspases, it is yet to be established if blocking caspase- 2 can reverse pre-existing disease. Interestingly, Casp $2^{-/}$mice have also been shown to be protected from streptozocin diabetes-induced bone marrow adiposity [73] suggesting depot-specific differences.

As described above, activation of caspase- 2 has been reported to increase with severity of NASH in patients [27] and $\mathrm{Casp}^{-/-}$mice are protected from the development of MCD-induced NASH (Table 1) [28]. While this implicates caspase-2 as an important mediator of apoptosis in NASH, no significant differences have been noticed in the levels of apoptosis in livers of normal Casp2 $2^{-/}$mice or following ethanol-induced liver injury [63], paraquat toxicity [68] or DEN-induced HCC [71]. In addition, although MCD-fed mice are protected from NASH, they still develop fatty liver [28]. Unlike HFD-feeding, the MCD is a nutrient-deprivation model of NASH resembling features of starvation [74]. Consistent with this, no differences were observed in fasting-induced liver steatosis [66] or alcohol-induced liver steatosis [63]. This suggests that caspase-2 does not alter FFA uptake and/or de novo lipogenesis in vivo, consistent with the lack of observed differences in lipogenic/FFA pathways [65, 66]. In contrast to these models, protection of $\mathrm{Casp}^{-/-}$mice from the development of DIO NAFLD is likely a secondary effect to overall protection from obesity. Thus, while these studies provide support for caspase- 2 as a potential therapeutic target in metabolic diseases, further preclinical animal studies are needed to validate such an approach.

Caspase-2 is an important regulator of genomic stability and maintenance of normal ploidy [75, 76]. Following cytokinesis failure, caspase- 2 has been shown to cleave MDM2, thus stabilising p53 and resulting in cell-cycle arrest [77]. Other findings suggest that caspase-2 prevents the accumulation of mitotically aberrant cells, such as aneuploidy cells, via its apoptosis function and caspase-2 deficiency in mice results in accumulation of aneuploidy cells in the bone marrow of aged knockout mice [76, 78]. As p53 and aneuploidy affect cellular metabolism, the link between caspase-2-augmented genomic stability and metabolism cannot be ruled out.

\section{Non-apoptotic roles of caspase-8 and necroptosis in metabolic disease}

Similar to Casp $2^{-/-}$mice, MCD-fed Casp $^{-/-}$mice show reduced development of NASH but not steatosis (Table 1) 
[79]. In contrast, hepatocyte-specific deletion of caspase-8 $\left(\operatorname{Casp} 8^{\Delta \text { hep }}\right)$ reduces both MCD-induced NASH and steatosis [80] and reverts the enhanced progression of MCDinduced NASH in $c$-Met knockout mice after 4 weeks of dietary feeding [81]. In addition, Casp $8^{\Delta \text { hep }}$ mice show reduced development of alcohol-induced steatosis [82]. Microarray analysis of liver from MCD-fed Casp $8^{\Delta \text { hep }}$ mice provided evidence that caspase- 8 may also have a non-apoptotic role in de novo lipogenesis and hepatic lipid storage and export [80]. However, in conflict with these findings, Gautheron et al. reported an increase in MCDinduced NASH (with no difference in steatosis) in liver parenchymal and hepatocyte-specific Casp 8 knockout mice (LPC, hepatocytes and cholangiocytes; $\operatorname{Casp} 8^{L P C-K O}$ ) [83]. This was reportedly due to increases in RIP3-dependent hepatocyte necroptosis which was suggested to promote NASH-induced liver fibrosis [83]. In addition to apoptosis, caspase-8 is required for suppression of necroptosis. Necroptosis (programmed necrosis) is a highly specific alternative cell death programme, dependent on RIP1 and RIP3 kinases, that is triggered downstream of the TNF receptor [84]. However, the role of necroptosis in human liver disease is controversial as it requires a block or absence of caspase- 8 and there is no evidence to suggest that caspase- 8 would be blocked in patients [84]. Additionally, intrinsic apoptosis can still be triggered in the absence of caspase- 8 , and as such, enhanced activation of caspase-9-mediated apoptosis was recently reported in hepatocytes of Casp $8^{\text {shepa }}$ mice following alcohol-induced liver injury that was ameliorated using a pan-caspase inhibitor [82]. Recently, in vivo pan-caspase inhibition using ZVAD-fmk was shown to initially reduce lipopolysaccharide/D-galactosamine (GalN)-induced hepatocellular apoptosis before triggering necrotic death after prolonged caspase inhibition [85]. Interestingly, pharmacological inhibition of RIPK1 by necrostatin or by genetic deletion of RIPK3 in the presence of ZVAD-fmk did not prevent necrosis but rather, exacerbated LPS/GalN/ZVD-induced liver injury. This study suggested that inhibition of caspases in liver injury can trigger a non-necroptotic caspaseindependent form of cell death [85].

Further adding to the controversy, a subsequent study by Gautheron et al. showed upregulation of RIP3 in obese WAT and by using choline-deficient HFD (CD-HFD) based on knockout animal studies, proposed that RIP3 plays a role in suppressing, not inducing, inflammation by blocking caspase-8-dependent adipocyte apoptosis [86]. However, it is still unclear how RIP3 acts to block caspase-8-induced apoptosis in this context.

As described above, cFLIP is an important regulator of caspase- 8 and helps maintain a balance between apoptotic and necroptotic modes of cell death [35]. In mice, hepatocyte-specific deletion of cFLIP increases susceptibility to liver injury that is accompanied by enhanced caspase activation, apoptosis and inflammation [87]. Furthermore, cFLIP has been identified as a critical suppressor of NASH and metabolic syndrome in animal models with CFLAR mimicking peptides reversing NASH and metabolic disorder in mice and monkeys [88]. However, this occurs via direct blocking of ASK1/JNK1 activation [88] and may not involve its interaction with caspase-8.

\section{Caspase substrates influencing de novo lipogenesis and adipogenesis}

Increased hepatic de novo lipogenesis is a common feature of NAFLD that can arise following activation of transcription factors such as SREBP-1 and PPAR $\gamma$ [89]. SREBP transcription factors are master regulators of lipid homoeostasis that are activated in response to cholesterol depletion, insulin stimulation and ER stress to transcriptionally upregulated genes involved in fatty-acid triglyceride, phospholipid and cholesterol synthesis [90]. Caspasemediated cleavage of SREBP occurs during apoptosis [42] and has been observed following in vitro incubation with recombinant caspase-3, -7, -4 and -12 [91, 92]. Caspase-1 has also been shown to cleave SREBP independent of cell death to enhance de novo lipogenesis and membrane biogenesis to possibly promote cell survival following hepatitis C viral-infection [93] or in response to the bacterial poreforming toxin aerolysin [94]. Whether NLRP3 inflammasome activation of caspase-1 also results in SREBP cleavage in the setting of obesity and/or NAFLD/NASH is not known; however, if cleavage results in activation of SREBP, and enhanced lipogenesis, then this is not a desirable outcome in the treatment of these metabolic diseases. Some evidence suggests that caspase- 3 may cleave SREBP2 in a non-apoptotic manner in response to NGF and pro-NGF stimulation of $\mathrm{p} 75$ neurotrophin receptor signalling to regulate low-density lipoprotein receptors (LDLRs) and lipid uptake [95]. Although human CASP2 gene was reported to be under transcriptional control of the SREBPs and involved in positive-feedback loop, recombinant caspase-2 does not cleave SREBPs [92].

PPAR $\gamma$ is also a key regulator of lipid metabolism and is an essential mediator of adipogenesis and adipose tissue function [96]. Caspase-mediated cleavage of PPAR $\gamma$, independent of apoptosis, has been observed in 3T3-L1 adipocytes with cleavage, resulting in deactivation of PPAR $\gamma$ and disruption of adipocyte metabolism by reducing the expression of lipogenic genes [97, 98]. He et al. observed caspase-1, but not caspase-3, -8 or -9 -mediated cleavage of PPAR $\gamma$, following TNF- $\alpha$ and cyclohexamide treatment of 3T3-L1 adipocytes [43]. In contrast, Guilherme 


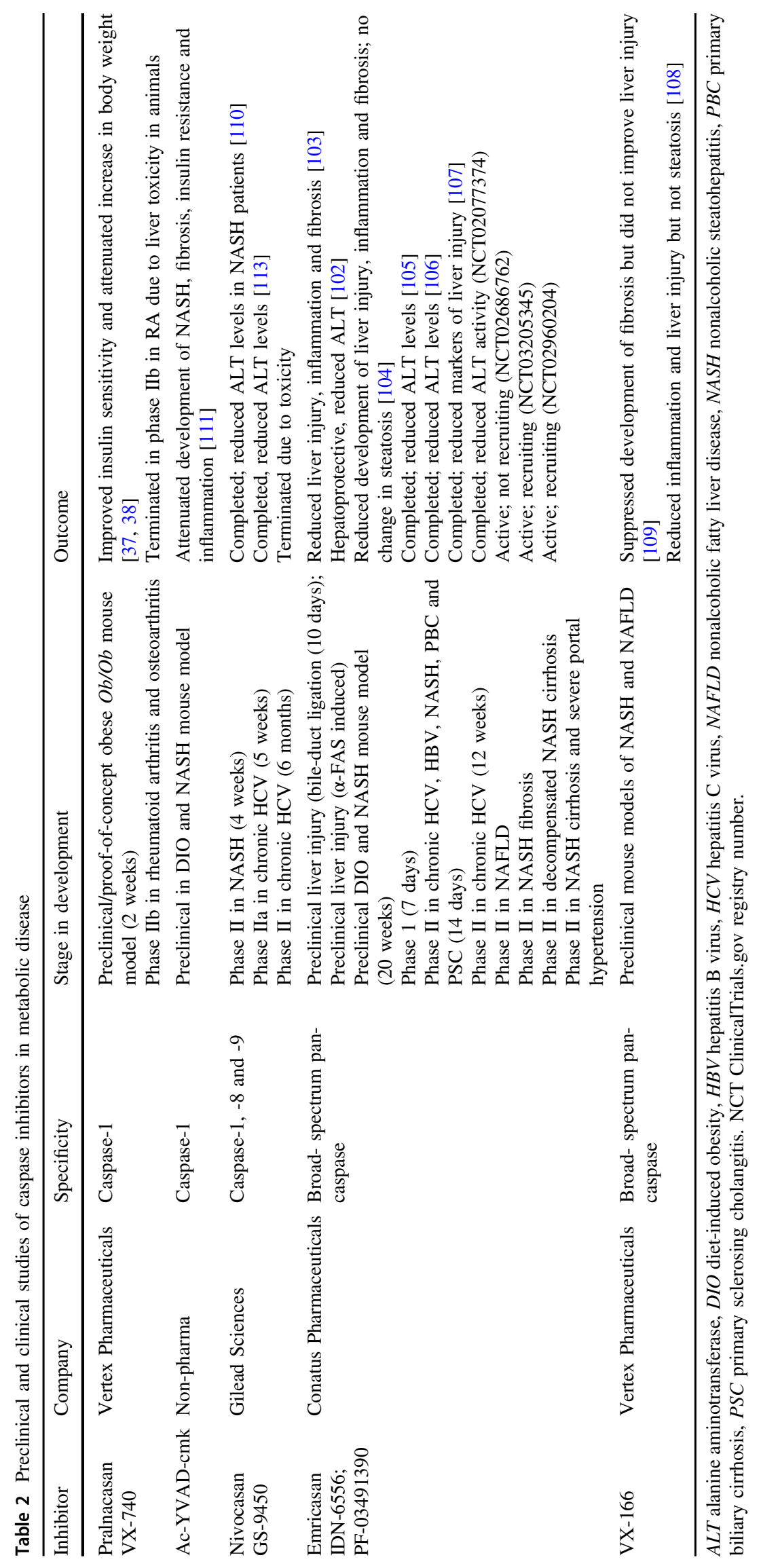


et al. observed caspase- $3,-6$ and -8 , but not caspase-1, -2 , $-5,-7$ or -9 that cleave PPAR $\gamma$ in response to TNF- $\alpha$ stimulation [97]. TRAIL was also shown to regulate adipocyte metabolism by activating caspase- 8 and -3 , which subsequently led to non-apoptotic cleavage of PPAR $\gamma[98,99]$. TRAIL can inhibit adipogenic differentiation of human SGBS preadipocytes and stromal-vascular cells isolated from human WAT in a dose-dependent manner by activating caspase- 8 and -3 , resulting in downregulation of $\mathrm{C} /$ EBP- $\alpha$, CEBP- $\sigma$ and PPAR $\gamma$ [100]. Caspase- 1 cleavage of PPAR $\gamma$ in tumour-associated macrophages, promotes tumour differentiation, progression and metastasis [101].

\section{Therapeutic targeting of caspases in metabolic disease}

Several preclinical and clinical studies provide promising evidence that pan-caspase inhibitors are of therapeutic value in blocking apoptosis in liver disease (Table 2) [24]. Emricasan (IDN-6556), an irreversible pan-caspase inhibitor, has shown efficacy in blocking hepatocellular apoptosis and attenuating liver injury, inflammation and fibrosis in animal models of liver injury and HFD-induced NASH (Table 2) [102-104]. Evaluation of Emricasan in phase I/II clinical trials has demonstrated that it is well-tolerated in humans following short-term treatment and improves the levels of liver marker enzymes, although these quickly returned to pre-treatment levels after drug discontinuation [105-107]. Phase-II trials investigating its use in NAFLD (NCT02077374) show reduction in liver injury (Table 2). Phase-II trials in NASH-associated fibrosis (but not cirrhosis) (NCT02686762), decompensated NASH cirrhosis (NCT03205345) and in patients with NASH cirrhosis and severe portal hypertension (NCT02960204) they are currently active (Table 2). Another irreversible pan-caspase inhibitor, VX-166, has also been shown to reduce hepatocellular apoptosis, inflammation and fibrosis in MCD- and HFD-models of NASH (Table 2) [108, 109]. VX-166 did not reduce hepatic steatosis in the MCD-diet model [108] but reduced hepatic triglyceride levels in the HFD-model, although no improvement in liver-injury markers was observed [108, 109]. GS-9450, an irreversible selective inhibitor of caspases-1, -8 and -9 , evaluated in a phase-II clinical trial in patients with NASH, is well tolerated in patients and reduces serum ALT levels (Table 2) [110]. However, a larger 6-month phase-II clinical trial in hepatitis $\mathrm{C}$ patients was later terminated due to drug-induced liver toxicity concerns (Table 2). As a stand-alone therapy, pancaspase inhibitors may have limited efficacy and would best be administered with other metabolic target therapies, such as thiazolidinediones (TZDs) or synthetic PPAR $\gamma$ agonist, that are geared to reduce hepatic fat accumulation and metabolic stress [5]. While promising, the long-term effects of pan-caspase inhibition need to be examined, especially with recent findings, also discussed above, from animal studies indicating enhancement of alternative cell death pathways. [82, 85] While evidence suggests that caspase-1, caspase- 2 and caspase- 8 can influence metabolism, independent of cell death, whether and how they may lead to metabolic disease onset and/or progression is not known.

In the context of obesity, the utility of targeting adipocyte apoptosis is yet to be investigated; however, tissuespecific targeting of non-apoptotic roles via selective caspase- 2 or caspase- 1 inhibition may be of more value. As indicated from animal studies, if ablation of caspase- 2 and/ or caspase- 1 can modulate the size of adipocytes and adipogenesis in obese adipose tissue, then their therapeutic inhibition may result in the promotion of healthier fat mass that may help improve the reduction of fat accumulation in combination with dietary and lifestyle interventions. In support of this concept, short-term (2-week) treatment of genetically obese $o b / o b$ mice with the caspase-1 inhibitor Pralnacasan has been shown to improve insulin sensitivity and attenuate increases in body weight (Table 2) [37]. However, a phase-IIb trial of Pralnacasan in rheumatoid arthritis patients was terminated due to liver toxicity in animals, although no adverse side effects were observed in trial participants [7]. In a separate preclinical study, caspase-1 inhibition, using AC-YVAD-cmk, in HFD-fed obese-diabetic LDLR $^{-/}$Leiden mice, reduced adipose tissue inflammation, prevented development of NASH and attenuated progression of insulin resistance but did not alter body-weight or dyslipidemia (Table 2) [111].

Despite being implicated in tumour suppression in mice, inhibition of caspase-2 appears to be safe as Casp2 $2^{-/-}$mice do not spontaneously develop tumours and have no overtly adverse phenotype [10]. Supporting the safety in targeting caspase-2, QPI-1007, a therapeutic naked siRNA targeting caspase-2, is currently being used in human phase-III clinical trials for the treatment of non-arteritic anterior ischaemic optic neuropathy (Quark Pharmaceuticals; http://qua rkpharma.com) [23]. In mouse studies, infusing an anticaspase-2 morpholino into mouse brain reduced caspase-2 protein levels and its cleavage of tau to reverse memory deficits without adverse effects [24]. To the best of our knowledge, there are currently no caspase- 2 selective inhibitors available although a patent has been filed for nasal administration of a peptide inhibitor, with the amino acid sequence AFDAFC, targeting caspase-2 for treatment of neurodegenerative disorders such as ALS, Creutzfeldt-Jacob disease, AD, MCI, PD and HD [6].

Due to the high overlap in substrate selectivity among caspases, the development of small-molecule inhibitors that specifically target caspases has remained challenging. Therefore, novel approaches utilising advanced drug 
delivery systems such as nanoparticles or liposomes in combination with siRNA-mediated knockdown or CRISPR-Cas9 gene editing should be a focus in future studies. As described above, a CASP2 siRNA has already reached a clinical trial and $C A S P 8$-specific siRNA has been shown to improve survival and attenuate liver damage induced by agnostic Fas (CD95) antibody (Jo2) or by adenovirus-expressing Fas ligand (AdFasL) [112]. However, since caspase- 8 knockout can still exhibit activation of the intrinsic apoptotic pathways, this may still result in increased necroptotic injury.

\section{Conclusions and perspectives}

The animal model studies summarised here suggest that some caspases have roles in metabolism and pathologies due to metabolic defects. However, in the absence of more detailed studies, it is still not fully clear if apoptotic, nonapoptotic or both functions of caspases are important in particular metabolic diseases. Furthermore, a cross-talk between alternate cell death pathways and modes of death that occur in the absence of caspases activity, including the risk of increasing inflammatory responses and further propagating metabolic disease needs to be more clearly established in preclinical models. A lack in our understanding as to the roles of caspases in human biology and metabolic disease also constrains the proper investigations of the therapeutic potential of targeting caspases. Novel approaches utilising human derived cells and induced pluripotent stem cell systems with CRISPR-Cas9 knockout are needed to elucidate the finding in humans. Nevertheless, the accumulated data derived from gene knockout in mice provide leads for further exploration, both for better understanding metabolic diseases and for opening new avenues for targeting them. Importantly, while animal studies show protection from disease and potential therapeutic value, there is still much work needed to be done to determine the precise mechanism of function and translation to human biology. In addition, while genetic deletion of a given caspase shows protection (or increased susceptibility) to DIO or MCD-induced obesity, the effect of ablating caspase function in pre-existing disease models and potential to reverse disease needs to be established. Although pan-caspase inhibitors are able to reduce liver injury, it is not yet known what effect, if any, there is on adipocyte biology and blood glucose/insulin resistance, and the longterm consequence and induction of alternate cell death pathways need further study. Better understanding of the cell death-independent roles and identification of substrates and signalling pathways not resulting in death may provide alternate means for therapeutic advantage.
Acknowledgements The caspase work in our laboratory was supported by the National Health and Medical Research Council (NHMRC) of Australia project grants 1021456 and 1043057, a NHMRC Early Career Research Fellowship to CHW (1073771) and a NHMRC Senior Principal Research Fellowship to SK (1103006).

\section{Compliance with ethical standards}

Conflict of interest The authors declare that they have no conflict of interest.

Open Access This article is licensed under a Creative Commons Attribution 4.0 International License, which permits use, sharing, adaptation, distribution and reproduction in any medium or format, as long as you give appropriate credit to the original author(s) and the source, provide a link to the Creative Commons license, and indicate if changes were made. The images or other third party material in this article are included in the article's Creative Commons license, unless indicated otherwise in a credit line to the material. If material is not included in the article's Creative Commons license and your intended use is not permitted by statutory regulation or exceeds the permitted use, you will need to obtain permission directly from the copyright holder. To view a copy of this license, visit http://creativecommons. org/licenses/by/4.0/.

\section{References}

1. Shalini S, Dorstyn L, Dawar S, Kumar S. Old, new and emerging functions of caspases. Cell Death Diff. 2015;22:526-39.

2. Lamkanfi M, Dixit VM. Mechanisms and functions of inflammasomes. Cell. 2014;157:1013-22.

3. Wree A, Broderick L, Canbay A, Hoffman HM, Feldstein AE. From NAFLD to NASH to cirrhosis-new insights into disease mechanisms. Nat Rev Gastroenterol Hepatol. 2013;10:627-36.

4. Alkhouri N, Gornicka A, Berk MP, Thapaliya S, Dixon LJ, Kashyap S, et al. Adipocyte apoptosis, a link between obesity, insulin resistance, and hepatic steatosis. J Biol Chem. 2010;285:3428-38.

5. Rotman Y, Sanyal AJ. Current and upcoming pharmacotherapy for non-alcoholic fatty liver disease. Gut. 2017;66:180-90.

6. Lee H, Shin EA, Lee JH, Ahn D, Kim CG, Kim JH, et al. Caspase inhibitors: a review of recently patented compounds (2013-2015). Expert Opin Ther Pat. 2018;28:47-59.

7. Kudelova J, Fleischmannova J, Adamova E, Matalova E. Pharmacological caspase inhibitors: research towards therapeutic perspectives. J Physiol Pharmacol. 2015;66:473-82.

8. Rosen ED, Spiegelman BM. What we talk about when we talk about fat. Cell. 2014;156:20-44.

9. Cusi K. Role of obesity and lipotoxicity in the development of nonalcoholic steatohepatitis: pathophysiology and clinical implications. Gastroenterology. 2012;142:711-25. e716

10. Strissel KJ, Stancheva Z, Miyoshi H, Perfield JW 2nd, DeFuria J, Jick Z, et al. Adipocyte death, adipose tissue remodeling, and obesity complications. Diabetes. 2007;56:2910-8.

11. Wang QA, Tao C, Gupta RK, Scherer PE. Tracking adipogenesis during white adipose tissue development, expansion and regeneration. Nat Med. 2013;19:1338-44.

12. Tinahones FJ, Coin Araguez L, Murri M, Oliva Olivera W, Mayas Torres MD, Barbarroja $\mathrm{N}$, et al. Caspase induction and BCL2 inhibition in human adipose tissue: a potential relationship with insulin signaling alteration. Diabetes Care. 2013;36:513-21. 
13. Cinti S, Mitchell G, Barbatelli G, Murano I, Ceresi E, Faloia E, et al. Adipocyte death defines macrophage localization and function in adipose tissue of obese mice and humans. J Lipid Res. 2005;46:2347-55

14. Giordano A, Murano I, Mondini E, Perugini J, Smorlesi A, Severi I, et al. Obese adipocytes show ultrastructural features of stressed cells and die of pyroptosis. J Lipid Res. 2013;54:2423-36.

15. Fischer-Posovszky P, Wang QA, Asterholm IW, Rutkowski JM, Scherer PE. Targeted deletion of adipocytes by apoptosis leads to adipose tissue recruitment of alternatively activated M2 macrophages. Endocrinology. 2011;152:3074-81.

16. Murano I, Rutkowski JM, Wang QA, Cho YR, Scherer PE, Cinti $\mathrm{S}$. Time course of histomorphological changes in adipose tissue upon acute lipoatrophy. Nutr Metab Cardiovasc Dis. 2013;23:723-31.

17. Bechmann LP, Hannivoort RA, Gerken G, Hotamisligil GS, Trauner M, Canbay A. The interaction of hepatic lipid and glucose metabolism in liver diseases. J Hepatol. 2012;56:952-64.

18. Perry RJ, Samuel VT, Petersen KF, Shulman GI. The role of hepatic lipids in hepatic insulin resistance and type 2 diabetes. Nature. 2014;510:84-91.

19. Canbay A, Taimr P, Torok N, Higuchi H, Friedman S, Gores GJ. Apoptotic body engulfment by a human stellate cell line is profibrogenic. Lab Invest. 2003;83:655-63.

20. Luedde T, Kaplowitz N, Schwabe RF. Cell death and cell death responses in liver disease: mechanisms and clinical relevance. Gastroenterology. 2014;147:765-83. e764

21. Feldstein AE, Canbay A, Angulo P, Taniai M, Burgart LJ, Lindor KD, et al. Hepatocyte apoptosis and fas expression are prominent features of human nonalcoholic steatohepatitis. Gastroenterology. 2003;125:437-43.

22. McIlwain DR, Berger T, Mak TW. Caspase functions in cell death and disease. Cold Spring Harb Perspect Biol. 2013; 5:a008656

23. Mota M, Banini BA, Cazanave SC, Sanyal AJ. Molecular mechanisms of lipotoxicity and glucotoxicity in nonalcoholic fatty liver disease. Metab Clin Exp. 2016;65:1049-61.

24. Wang K. Molecular mechanisms of hepatic apoptosis. Cell Death Dis. 2014;5:e996.

25. Malhi H, Barreyro FJ, Isomoto H, Bronk SF, Gores GJ. Free fatty acids sensitise hepatocytes to TRAIL mediated cytotoxicity. Gut. 2007;56:1124-31.

26. Malhi H, Bronk SF, Werneburg NW, Gores GJ. Free fatty acids induce JNK-dependent hepatocyte lipoapoptosis. J Biol Chem. 2006;281:12093-101.

27. Ferreira DM, Castro RE, Machado MV, Evangelista T, Silvestre A, Costa A, et al. Apoptosis and insulin resistance in liver and peripheral tissues of morbidly obese patients is associated with different stages of non-alcoholic fatty liver disease. Diabetologia. 2011;54:1788-98.

28. Machado MV, Michelotti GA, Pereira Tde A, Boursier J, Kruger L, Swiderska-Syn M, et al. Reduced lipoapoptosis, hedgehog pathway activation and fibrosis in caspase- 2 deficient mice with non-alcoholic steatohepatitis. Gut. 2015;64:1148-57.

29. Galluzzi L, Vitale I, Aaronson SA, Abrams JM, Adam D, Agostinis P, et al. Molecular mechanisms of cell death: recommendations of the Nomenclature Committee on Cell Death 2018. Cell Death Diff. 2018. https://doi.org/10.1038/ s41418-017-0012-4

30. Kovacs SB, Miao EA. Gasdermins: effectors of pyroptosis. Trends Cell Biol. 2017;27:673-84.

31. Rogers C, Fernandes-Alnemri T, Mayes L, Alnemri D, Cingolani G, Alnemri ES. Cleavage of DFNA5 by caspase-3 during apoptosis mediates progression to secondary necrotic/pyroptotic cell death. Nat Commun. 2017;8:14128.

32. Jorgensen I, Rayamajhi M, Miao EA. Programmed cell death as a defence against infection. Nat Rev Immunol. 2017;17:151-64.

33. White MJ, McArthur K, Metcalf D, Lane RM, Cambier JC, Herold MJ, et al. Apoptotic caspases suppress mtDNA-induced STING-mediated type I IFN production. Cell. 2014;159:1549-62.

34. O'Donnell MA, Perez-Jimenez E, Oberst A, Ng A, Massoumi R, Xavier R, et al. Caspase 8 inhibits programmed necrosis by processing CYLD. Nat Cell Biol. 2011;13:1437-42.

35. Oberst A, Dillon CP, Weinlich R, McCormick LL, Fitzgerald P, Pop C, et al. Catalytic activity of the caspase-8-FLIP(L) complex inhibits RIPK3-dependent necrosis. Nature. 2011;471:363-7.

36. Vandanmagsar B, Youm YH, Ravussin A, Galgani JE, Stadler K, Mynatt RL, et al. The NLRP3 inflammasome instigates obesityinduced inflammation and insulin resistance. Nat Med. 2011;17:179-88.

37. Stienstra R, Joosten LA, Koenen T, van Tits B, van Diepen JA, van den Berg SA, et al. The inflammasome-mediated caspase-1 activation controls adipocyte differentiation and insulin sensitivity. Cell Metab. 2010;12:593-605.

38. Stienstra R, van Diepen JA, Tack CJ, Zaki MH, van de Veerdonk FL, Perera D, et al. Inflammasome is a central player in the induction of obesity and insulin resistance. Proc Natl Acad Sci USA. 2011;108:15324-9.

39. Koenen TB, Stienstra R, van Tits LJ, de Graaf J, Stalenhoef AF, Joosten LA, et al. Hyperglycemia activates caspase-1 and TXNIP-mediated IL-1beta transcription in human adipose tissue. Diabetes. 2011;60:517-24.

40. Shi J, Zhao Y, Wang K, Shi X, Wang Y, Huang H, et al. Cleavage of GSDMD by inflammatory caspases determines pyroptotic cell death. Nature. 2015;526:660-5.

41. Shao W, Yeretssian G, Doiron K, Hussain SN, Saleh M. The caspase-1 digestome identifies the glycolysis pathway as a target during infection and septic shock. J Biol Chem. 2007;282:36321-9.

42. Wang X, Zelenski NG, Yang J, Sakai J, Brown MS, Goldstein JL. Cleavage of sterol regulatory element binding proteins (SREBPs) by CPP32 during apoptosis. EMBO J. 1996;15:1012-20.

43. He F, Doucet JA, Stephens JM. Caspase-mediated degradation of PPARgamma proteins in adipocytes. Obesity. 2008;16:1735-41.

44. Kayagaki N, Warming S, Lamkanfi M, Vande Walle L, Louie S, Dong $\mathrm{J}$, et al. Non-canonical inflammasome activation targets caspase-11. Nature. 2011;479:117-21.

45. Skeldon AM, Morizot A, Douglas T, Santoro N, Kursawe R, Kozlitina $\mathrm{J}$, et al. Caspase-12, but not Caspase-11, inhibits obesity and insulin resistance. J Immunol. 2016;196:437-47.

46. van Diepen JA, Stienstra R, Vroegrijk IO, van den Berg SA, Salvatori D, Hooiveld GJ, et al. Caspase-1 deficiency in mice reduces intestinal triglyceride absorption and hepatic triglyceride secretion. J Lipid Res. 2013;54:448-56.

47. Kotas ME, Jurczak MJ, Annicelli C, Gillum MP, Cline GW, Shulman GI, et al. Role of caspase-1 in regulation of triglyceride metabolism. Proc Natl Acad Sci USA. 2013;110:4810-5.

48. Kimura H, Karasawa T, Usui F, Kawashima A, Endo Y, Kobayashi M, et al. Caspase-1 deficiency promotes high-fat dietinduced adipose tissue inflammation and the development of obesity. Am J Physiol Endocrinol Metab. 2016;311:E881-E890.

49. Wang H, Capell W, Yoon JH, Faubel S, Eckel RH. Obesity development in caspase-1-deficient mice. Int $\mathrm{J}$ Obes (Lond). 2014;38:152-5.

50. Dixon LJ, Flask CA, Papouchado BG, Feldstein AE, Nagy LE. Caspase-1 as a central regulator of high fat diet-induced nonalcoholic steatohepatitis. PLoS ONE. 2013;8:e56100.

51. Wree A, Eguchi A, McGeough MD, Pena CA, Johnson CD, Canbay A, et al. NLRP3 inflammasome activation results in 
hepatocyte pyroptosis, liver inflammation, and fibrosis in mice. Hepatology. 2014;59:898-910.

52. Henao-Mejia J, Elinav E, Jin C, Hao L, Mehal WZ, Strowig T, et al. Inflammasome-mediated dysbiosis regulates progression of NAFLD and obesity. Nature. 2012;482:179-85.

53. Lebeaupin C, Proics E, de Bieville CH, Rousseau D, Bonnafous $\mathrm{S}$, Patouraux S, et al. ER stress induces NLRP3 inflammasome activation and hepatocyte death. Cell Death Dis. 2015;6:e1879.

54. Fu S, Watkins SM, Hotamisligil GS. The role of endoplasmic reticulum in hepatic lipid homeostasis and stress signaling. Cell Metab. 2012;15:623-34.

55. Hetz C, Papa FR. The unfolded protein response and cell fate control. Mol Cell. 2018;69:169-81.

56. Upton JP, Austgen K, Nishino M, Coakley KM, Hagen A, Han D, et al. Caspase-2 cleavage of BID is a critical apoptotic signal downstream of endoplasmic reticulum stress. Mol Cell Biol. 2008;28:3943-51.

57. Sandow JJ, Dorstyn L, O'Reilly LA, Tailler M, Kumar S, Strasser A, et al. ER stress does not cause upregulation and activation of caspase-2 to initiate apoptosis. Cell Death Diff. 2014;21:475-80.

58. Scott AM, Saleh M. The inflammatory caspases: guardians against infections and sepsis. Cell Death Diff. 2007;14:23-31.

59. Saleh M, Mathison JC, Wolinski MK, Bensinger SJ, Fitzgerald P, Droin N, et al. Enhanced bacterial clearance and sepsis resistance in caspase-12-deficient mice. Nature. 2006;440:1064-8.

60. Yeretssian G, Doiron K, Shao W, Leavitt BR, Hayden MR, Nicholson DW, et al. Gender differences in expression of the human caspase-12 long variant determines susceptibility to Listeria monocytogenes infection. Proc Natl Acad Sci USA. 2009;106:9016-20.

61. Saleh M, Vaillancourt JP, Graham RK, Huyck M, Srinivasula SM, Alnemri ES, et al. Differential modulation of endotoxin responsiveness by human caspase-12 polymorphisms. Nature. 2004;429:75-79.

62. Miles MA, Kitevska-Ilioski T, Hawkins CJ. Old and novel functions of caspase-2. Int Rev Cell Mol Biol. 2017;332:155-212.

63. Shalini S, Dorstyn L, Wilson C, Puccini J, Ho L, Kumar S. Impaired antioxidant defence and accumulation of oxidative stress in caspase-2-deficient mice. Cell Death Diff. 2012;19:1370-80.

64. Zhang YP, Padalecki SS, Chaudhuri AR, De Waal E, Goins BA, Grubbs B, et al. Caspase-2 deficiency enhances aging-related traits in mice. Mech Ageing Dev. 2007;128:213-21.

65. Wilson CH, Nikolic A, Kentish SJ, Keller M, Hatzinikolas G, Dorstyn L, et al. Caspase-2 deficiency enhances whole-body carbohydrate utilisation and prevents high-fat diet-induced obesity. Cell Death Dis. 2017;8:e3136.

66. Wilson $\mathrm{CH}$, Nikolic A, Kentish SJ, Shalini S, Hatzinikolas G, Page AJ, et al. Sex-specific alterations in glucose homeostasis and metabolic parameters during ageing of caspase-2-deficient mice. Cell Death Discov. 2016;2:16009.

67. Machado MV, Michelotti GA, Jewell ML, Pereira TA, Xie G, Premont RT, et al. Caspase- 2 promotes obesity, the metabolic syndrome and nonalcoholic fatty liver disease. Cell Death Dis. 2016; 7:e2096.

68. Shalini S, Puccini J, Wilson CH, Finnie J, Dorstyn L, Kumar S. Caspase-2 protects against oxidative stress in vivo. Oncogene. 2015;34:4995-5002.

69. Johnson ES, Lindblom KR, Robeson A, Stevens RD, Ilkayeva OR, Newgard CB, et al. Metabolomic profiling reveals a role for caspase-2 in lipoapoptosis. J Biol Chem. 2013;288:14463-75.

70. Lin CF, Chen CL, Chang WT, Jan MS, Hsu LJ, Wu RH, et al. Sequential caspase- 2 and caspase- 8 activation upstream of mitochondria during ceramideand etoposide-induced apoptosis. J Biol Chem. 2004;279:40755-61.
71. Shalini S, Nikolic A, Wilson CH, Puccini J, Sladojevic N, Finnie J, et al. Caspase-2 deficiency accelerates chemically induced liver cancer in mice. Cell Death Diff. 2016;23:1727-36.

72. Wilson CH, Shalini S, Filipovska A, Richman TR, Davies S, Martin SD, et al. Age-related proteostasis and metabolic alterations in Caspase-2-deficient mice. Cell Death Dis. 2015;6:e1615.

73. Coe LM, Lippner D, Perez GI, McCabe LR. Caspase-2 deficiency protects mice from diabetes-induced marrow adiposity. J Cell Biochem. 2011;112:2403-11.

74. Hebbard L, George J. Animal models of nonalcoholic fatty liver disease. Nat Rev Gastroenterol Hepatol. 2011;8:35-44.

75. Dorstyn L, Puccini J, Wilson CH, Shalini S, Nicola M, Moore S, et al. Caspase-2 deficiency promotes aberrant DNA-damage response and genetic instability. Cell Death Diff. 2012;19:1288-98.

76. Dawar S, Lim Y, Puccini J, White M, Thomas P, BouchierHayes L, et al. Caspase-2-mediated cell death is required for deleting aneuploid cells. Oncogene. 2017;36:2704-14.

77. Fava LL, Schuler F, Sladky V, Haschka MD, Soratroi C, Eiterer L, et al. The PIDDosome activates p53 in response to supernumerary centrosomes. Genes Dev. 2017;31:34-45.

78. Dawar S, Shahrin NH, Sladojevic N, D'Andrea RJ, Dorstyn L, Hiwase DK, et al. Impaired haematopoietic stem cell differentiation and enhanced skewing towards myeloid progenitors in aged caspase-2-deficient mice. Cell Death Dis. 2016;7:e2509.

79. Thapaliya S, Wree A, Povero D, Inzaugarat ME, Berk M, Dixon L, et al. Caspase 3 inactivation protects against hepatic cell death and ameliorates fibrogenesis in a diet-induced NASH model. Dig Dis Sci. 2014;59:1197-206.

80. Hatting M, Zhao G, Schumacher F, Sellge G, Al Masaoudi M, Gabetaler N, et al. Hepatocyte caspase- 8 is an essential modulator of steatohepatitis in rodents. Hepatology. 2013;57:2189-201.

81. Kroy DC, Schumacher F, Ramadori P, Hatting M, Bergheim I, Gassler N, et al. Hepatocyte specific deletion of c-Met leads to the development of severe non-alcoholic steatohepatitis in mice. J Hepatol. 2014;61:883-90.

82. Hao F, Cubero FJ, Ramadori P, Liao L, Haas U, Lambertz D, et al. Inhibition of Caspase-8 does not protect from alcoholinduced liver apoptosis but alleviates alcoholic hepatic steatosis in mice. Cell Death Dis. 2017;8:e3152.

83. Gautheron J, Vucur M, Reisinger F, Cardenas DV, Roderburg C, Koppe C, et al. A positive feedback loop between RIP3 and JNK controls non-alcoholic steatohepatitis. EMBO Mol Med. 2014;6:1062-74.

84. Dara L, Liu ZX, Kaplowitz N. Questions and controversies: the role of necroptosis in liver disease. Cell Death Discov. 2016;2:16089.

85. Ni HM, McGill MR, Chao X, Woolbright BL, Jaeschke H, Ding WX. Caspase inhibition prevents tumor necrosis factor-alphainduced apoptosis and promotes necrotic cell death in mouse hepatocytes in vivo and in vitro. Am J Pathol. 2016;186:2623-36.

86. Gautheron J, Vucur M, Schneider AT, Severi I, Roderburg C, Roy S, et al. The necroptosis-inducing kinase RIPK3 dampens adipose tissue inflammation and glucose intolerance. Nat Commun. 2016;7:11869.

87. Kohl T, Gehrke N, Schad A, Nagel M, Worns MA, Sprinzl MF, et al. Diabetic liver injury from streptozotocin is regulated through the caspase- 8 homolog cFLIP involving activation of JNK2 and intrahepatic immunocompetent cells. Cell Death Dis. 2013;4:e712.

88. Wang PX, Ji YX, Zhang XJ, Zhao LP, Yan ZZ, Zhang P, et al. Targeting CASP8 and FADD-like apoptosis regulator ameliorates nonalcoholic steatohepatitis in mice and nonhuman primates. Nat Med. 2017;23:439-49. 
89. Buzzetti E, Pinzani M, Tsochatzis EA. The multiple-hit pathogenesis of non-alcoholic fatty liver disease (NAFLD). Metab Clin Exp. 2016;65:1038-48.

90. Shao W, Espenshade PJ. Expanding roles for SREBP in metabolism. Cell Metab. 2012;16:414-9.

91. Pastorino JG, Shulga N. Tumor necrosis factor-alpha can provoke cleavage and activation of sterol regulatory elementbinding protein in ethanol-exposed cells via a caspase-dependent pathway that is cholesterol insensitive. J Biol Chem. 2008;283:25638-49.

92. Logette E, Le Jossic-Corcos C, Masson D, Solier S, SequeiraLegrand A, Dugail I, et al. Caspase-2, a novel lipid sensor under the control of sterol regulatory element binding protein 2. Mol Cell Biol. 2005;25:9621-31.

93. McRae S, Iqbal J, Sarkar-Dutta M, Lane S, Nagaraj A, Ali N, et al. The Hepatitis C virus-induced NLRP3 inflammasome activates the sterol regulatory element-binding protein (SREBP) and regulates lipid metabolism. J Biol Chem. 2016;291:3254-67.

94. Gurcel L, Abrami L, Girardin S, Tschopp J, van der Goot FG. Caspase-1 activation of lipid metabolic pathways in response to bacterial pore-forming toxins promotes cell survival. Cell. 2006; $126: 1135-45$.

95. Pham DD, Do HT, Bruelle C, Kukkonen JP, Eriksson O, Mogollon I, et al. p75 neurotrophin receptor signaling activates sterol regulatory element-binding Protein-2 in hepatocyte cells via p38 mitogen-activated protein kinase and caspase-3. J Biol Chem. 2016;291:10747-58.

96. Farmer SR. Transcriptional control of adipocyte formation. Cell Metab. 2006;4:263-73.

97. Guilherme A, Tesz GJ, Guntur KV, Czech MP. Tumor necrosis factor-alpha induces caspase-mediated cleavage of peroxisome proliferator-activated receptor gamma in adipocytes. J Biol Chem. 2009;284:17082-91.

98. Keuper M, Wernstedt Asterholm I, Scherer PE, Westhoff MA, Moller P, Debatin KM, et al. TRAIL (TNF-related apoptosisinducing ligand) regulates adipocyte metabolism by caspasemediated cleavage of PPARgamma. Cell Death Dis. 2013;4:e474.

99. Funcke JB, Zoller V, El Hay MA, Debatin KM, Wabitsch M, Fischer-Posovszky P. TNF-related apoptosis-inducing ligand promotes human preadipocyte proliferation via ERK1/2 activation. FASEB J. 2015;29:3065-75.

100. Zoller V, Funcke JB, Keuper M, Abd El Hay M, Debatin KM, Wabitsch M, et al. TRAIL (TNF-related apoptosis-inducing ligand) inhibits human adipocyte differentiation via caspasemediated downregulation of adipogenic transcription factors. Cell Death Dis. 2016;7:e2412.

101. Niu Z, Shi Q, Zhang W, Shu Y, Yang N, Chen B, et al. Caspase1 cleaves PPARgamma for potentiating the pro-tumor action of TAMs. Nat Commun. 2017;8:766.

102. Ueno Y, Ohmi T, Yamamoto M, Kato N, Moriguchi Y, Kojima $\mathrm{M}$, et al. Orally-administered caspase inhibitor PF-03491390 is retained in the liver for prolonged periods with low systemic exposure, exerting a hepatoprotective effect against alpha-fasinduced liver injury in a mouse model. J Pharmacol Sci. 2007;105:201-5.

103. Canbay A, Feldstein A, Baskin-Bey E, Bronk SF, Gores GJ. The caspase inhibitor IDN-6556 attenuates hepatic injury and fibrosis in the bile duct ligated mouse. J Pharmacol Exp Ther. 2004;308:1191-6.

104. Barreyro FJ, Holod S, Finocchietto PV, Camino AM, Aquino JB, Avagnina A, et al. The pan-caspase inhibitor Emricasan (IDN-6556) decreases liver injury and fibrosis in a murine model of non-alcoholic steatohepatitis. Liv Int. 2015;35:953-66.

105. Valentino KL, Gutierrez M, Sanchez R, Winship MJ, Shapiro DA. First clinical trial of a novel caspase inhibitor: anti-apoptotic caspase inhibitor, IDN-6556, improves liver enzymes. Int J Clin Pharmacol. 2003;41:441-9.

106. Pockros PJ, Schiff ER, Shiffman ML, McHutchison JG, Gish RG, Afdhal NH, et al. Oral IDN-6556, an antiapoptotic caspase inhibitor, may lower aminotransferase activity in patients with chronic hepatitis C. Hepatology. 2007;46:324-9.

107. Shiffman ML, Pockros P, McHutchison JG, Schiff ER, Morris M, Burgess G. Clinical trial: the efficacy and safety of oral PF03491390, a pancaspase inhibitor-a randomized placebocontrolled study in patients with chronic hepatitis C. Aliment Pharmacol Ther. 2010;31:969-78.

108. Anstee QM, Concas D, Kudo H, Levene A, Pollard J, Charlton P, et al. Impact of pan-caspase inhibition in animal models of established steatosis and non-alcoholic steatohepatitis. J Hepatol. 2010;53:542-50.

109. Witek RP, Stone WC, Karaca FG, Syn WK, Pereira TA, Agboola KM, et al. Pan-caspase inhibitor VX-166 reduces fibrosis in an animal model of nonalcoholic steatohepatitis. Hepatology. 2009;50:1421-30.

110. Ratziu V, Sheikh MY, Sanyal AJ, Lim JK, Conjeevaram H, Chalasani $\mathrm{N}$, et al. A phase 2, randomized, double-blind, placebo-controlled study of GS-9450 in subjects with nonalcoholic steatohepatitis. Hepatology. 2012;55:419-28.

111. Morrison MC, Mulder P, Salic K, Verheij J, Liang W, van Duyvenvoorde $\mathrm{W}$, et al. Intervention with a caspase- 1 inhibitor reduces obesity-associated hyperinsulinemia, non-alcoholic steatohepatitis and hepatic fibrosis in LDLR-/-.Leiden mice. Int J Obes. 2016;40:1416-23.

112. Zender L, Hutker S, Liedtke C, Tillmann HL, Zender S, Mundt B, et al. Caspase 8 small interfering RNA prevents acute liver failure in mice. Proc Natl Acad Sci USA. 2003;100:7797-802.

113. Manns MP, Lawitz E, Hoepelman A, Choi HJ, Lee JY, Cornpropst M. et al. 273 Short term safety, tolerability, pharmacokinetics and preliminary activity of gs-9450, a selective caspase inhibitor, in patients with chronic hev infection. Hepatology. 2010;52(Suppl 1):S133 